\title{
Land Cover Classification of Hail-Saudi Arabia Using Remote Sensing
}

\author{
Mohamed E. Hereher ${ }^{1,2}$, Ahmed M. Al-Shammari ${ }^{1}$, Shehta E. Abd Allah ${ }^{1,3}$ \\ ${ }^{1}$ Biology Department, Faculty of Science, The University of Hail, Hail, KSA \\ ${ }^{2}$ Department of Environmental Sciences, Faculty of Science at Damietta, Mansoura University, Damietta, Egypt \\ ${ }^{3}$ Geology Department, Faculty of Science, Zagazig University, Zagazig, Egypt \\ Email: mhereher@yahoo.com
}

Received January 10, 2012; revised February 16, 2012; accepted March 16, 2012

\begin{abstract}
A set of five satellite images from the Landsat satellite, Moderate Resolution Imaging Spectroradiometer (MODIS) and the Shuttle Radar Topography Mission (SRTM) sensors has been operated to analyze land cover and topography of the Hail region, Saudi Arabia. Image processing techniques included unsupervised classification for clustering four land cover units in the MODIS image, namely: plains, sand dunes, mountains, and cultivated lands. The SRTM image was classified to produce a thematic topographic map with $100 \mathrm{~m}$ elevation interval. The normalized difference vegetation index (NDVI) was applied in the Landsat images as a proxy to the change of agricultural land in Hail between 1972 and 2000. Results showed that Hail region occurs at a high plateau. Minimum elevation occurs at its northeastern corner and peaks occur at the southwestern side. The surface area of Hail is estimated at $115,690 \mathrm{~km}^{2}$. The majority of Hail area is represented by plains and sand dunes. Cultivated lands increased from 9500 ha in 1972 to 139,000 ha in 2010 .
\end{abstract}

Keywords: Land Cover; Remote Sensing; Hail; KSA

\section{Introduction}

Remote sensing has been successfully applied in many land cover classification and land use change detection studies using different generations of satellite images with diverse spatial, spectral and radiometric resolutions [1-3]. This accomplishment is attributed to many advantages afforded by remote sensing, such as the extensive geographic coverage of satellite image, the several spectral bands in each image and the stereoscopic view of some sensors. The premise in using satellite remote sensing in land cover change detection is based on the availability of archived digital data since early 1970s. The Landsat program provided successive generations of satellites since 1972 to explore earth resources on a systematic and repetitive basis. Among the sensors onboard the Landsat satellite are the Multi-Spectral Scanner (MSS), Thematic Mapper (TM) and the Enhanced Thematic Mapper Plus (ETM+). The wide geographic coverage is an important advantage of satellite remote sensing. For example, MODIS images cover as wide as $2330 \times 2330$ $\mathrm{km}$ of terrain, giving the opportunity of regional reconnaissance. MODIS, which was launched in Dec. 1999, sweeps the entire earth daily and records the reflected electromagnetic radiation in 36 spectral bands ranging from the visible to the thermal infrared wavelengths at $250 \mathrm{~m}, 500 \mathrm{~m}$ and $1000 \mathrm{~m}$ spatial resolution [4]. In addi- tion, MODIS products, such as the vegetation index (MOD13Q1), afford supplementary information about terrestrial vegetation conditions. Some other satellites, such as the Shuttle Radar Topography Mission (SRTM) onboard the Space Shuttle Endeavor, provided radar images on a stereoscopic basis, which means that the same area of terrain was subjected to radar waves and then the reflected waves were received at the same time by two separated sensors mounted at two antennas at the space shuttle. This stereoscopic imaging produced digital images of the earth's topography. Digital Elevation Models (DEM) are provided in $30 \mathrm{~m}, 90 \mathrm{~m}$ and $1000 \mathrm{~m}$ spatial resolutions. SRTM DEM images $(90 \mathrm{~m})$ had been successfully used to analyze topographic variations of the Nile Delta of Egypt in relation to sea level rise [5].

There are various ways of processing raw satellite data to infer information about land cover and land use changes. Among these techniques is the unsupervised classification algorithm, which statistically clusters analogous pixels without previous knowledge of the existence land cover units. The unsupervised classification involves two processes: clustering and labeling. The unsupervised classification was successfully applied using Landsat images for mapping land cover changes at Siwa Oasis, Egypt [6]. Vegetation indices are mathematical algorithms utilized for land cover changes, particularly in cul- 
tivated lands as they are surrogates to the abundance and activity of the green vegetation [7]. The NDVI, which is calculated as (NIR - Red)/(NIR + Red) [8] is the most famous, where the Red and NIR are the reflectance in the red and near infrared portions of the spectrum, respectively. Theoretically, NDVI takes values from -1.0 to +1.0 . Really, green vegetation has high index value (close to +1 ) and non-vegetation landscapes have low and negative index value.

There are numerous studies of remote sensing applications in arid regions, particularly for monitoring vegetation conditions and soil degradation $[9,10]$. To date, no systematic research has been conducted to operate remote sensing for land use/land cover studies in Hail region, Saudi Arabia. Consequently, the main objective of the present study is to utilize satellite images with regional coverage and different spatial resolutions for mapping land cover units of this desert region. Agricultural area change detection in the region is a minor objective in this investigation.

\section{Materials and Methods}

\subsection{The Study Area}

Hail occurs at a wide plateau overlying Precambrian elevated complex of igneous and metamorphic rock units known as the Arabian Shield. Hail region is characterized by its variation in topography and geomorphology. The northern part of the province is covered by the Great Nafud Sand Sea, which is the second largest sand sea in Arabia. The southern side is underlain by resistant rugged igneous and metamorphic mountain chains. Between these two geomorphologic landscapes, there are plain expanses hosting the most urban and agricultural land of the region. Historical locations in Hail reveal the importance of this region not only during the Islamic era, but even much earlier. Hail region is bordered from the north by Al-Juf and Northern Frontiers; from the west by Tabuk and Al-Madinah Al-Monawara; from the south by Al-Qasim and from the east by the Central and Eastern regions (Figure 1).

The capital of the province; Hail City, lies at the central part of the region. The city occurs at the foot of Aja Mountain which attains a height of $1480 \mathrm{~m}$ above sea level [11]. Groundwater is the sole source for irrigation, where deep wells extract water from the Saq sandstone aquifer, which extends for $1200 \mathrm{~km}$ in a northwestsoutheast direction and forms one of the most important aquifer in Arabia [12]. Natural vegetation includes typical desert flora (Xerophytes) which are shrubs and grasses restricted to ephemeral streams.

Climatic data of Hail as provided by the Saudi Ministry of Defense and Aviation reveal an arid to extremely arid pattern. Precipitation approaches $110 \mathrm{~mm}$ with two peaks of rainfall at March and November. The mean annual temperature is $23^{\circ} \mathrm{C}$. Sometimes summer temperatures approach more than $40^{\circ} \mathrm{C}$. Wind blows solely from two main directions: the north during summer and the south during the rest of the year with a mean wind speed of 6 knots. The mean annual relative humidity is $33 \%$ as Hail occurs far from the main water bodies in the region; i.e. the Red Sea and the Arabian Gulf. During summer, relative humidity becomes as low as $17 \%$ and it approaches 54\% during January. Annual evaporation rates at the central part of Saudi Arabia, including Hail, approach $3480 \mathrm{~mm}[13]$.

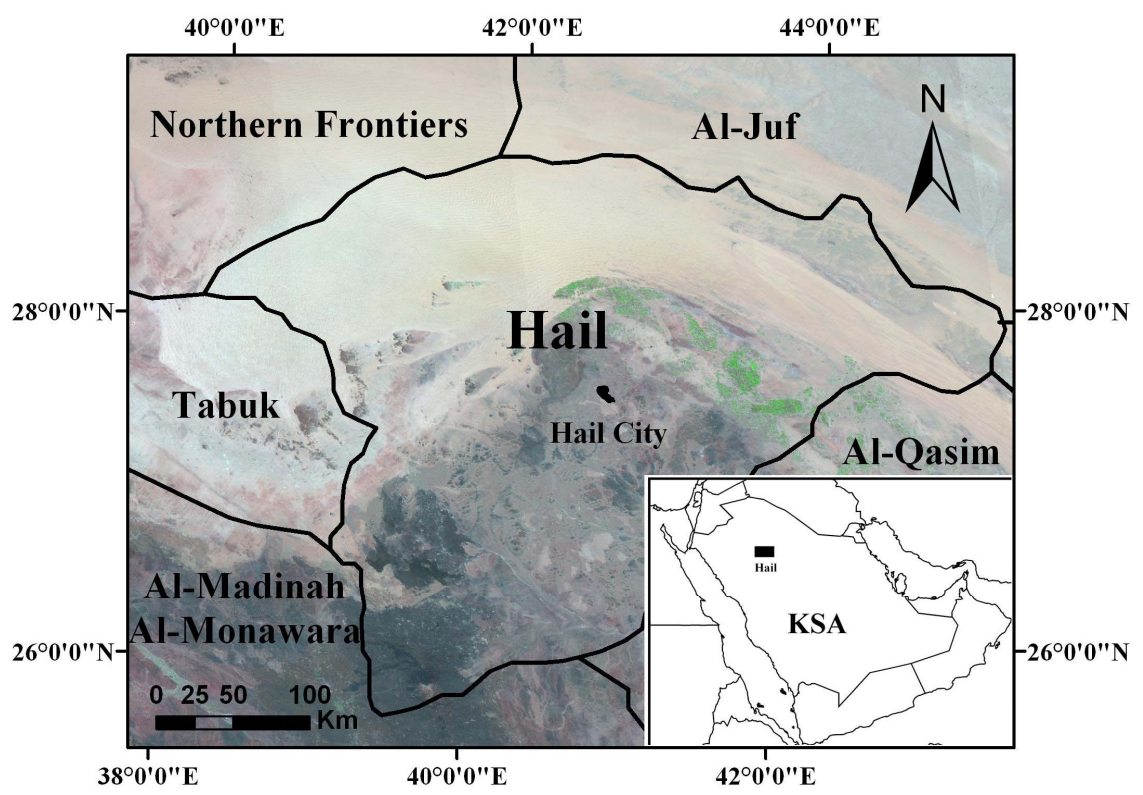

Figure 1. False color composite of MODIS image showing the location of Hail region in KSA. 


\subsection{Satellite Data}

A set of five satellite images from the MSS (1972), TM (1987), ETM+ (2000), SRTM (2000) and MODIS (2010) sensors had been provided to map the land cover diversity of Hail. These satellites were chosen because they are available and sufficient enough to cover the study area in terms of their temporal coverage and spatial resolutions. The spectral, spatial and ground coverage of each image are shown in Table 1. The Landsat images (MSS, TM, and ETM+) have a Universal Transverse Mercator projection (WGS-84), the MODIS image has a Sinusoidal projection (WGS-84) and the SRTM DEM has a Geographic (Lat/Long) projection. The MSS image consists of four spectral bands (one in the green, one in the red and two in the near infrared spectra).

The TM and ETM+ images consist of basic seven bands (one in the blue, one in the green, one in the red, two in the near infrared, one in the middle infrared and one in the thermal portion). The MODIS Vegetation Index product (MOD13Q1) image consist of 12 spectral bands including a blue, red, near infrared (NIR) and middle infrared (MIR) bands along with other vegetation indices and quality bands. The SRTM is a single-band image revealing the elevation in meters. The coarse spatial resolution SRTM image $(1000 \mathrm{~m})$ was used because it provides a seamless regional coverage.

\subsection{Image Pre-Processing}

We have utilized ERDAS Imagine and ArcGIS Software to process satellite images used in this study. The first step in image pre-processing was to unify the map projection of all images to a unique projection so that there is a geographic consistency of the data set. This was done using the Reproject Image function in ERDAS Imagine. We changed the map projection of the MODIS and SRTM images to the Universal Transverse Mercator (UTM-WGS 84) projection. The second step was applying the atmospheric correction to the data set. The MODIS image was originally corrected for any atmospheric interference (clouds, dust, haze, etc.). For the Landsat images, the dark object subtraction method [14] was applied. However, as each image of the satellite data was processed independently, there was no need to fur- ther radiometric correction [15]. The third step was creating a new subset image containing Hail region in each MODIS and SRTM image using the Area of Interest (AOI) function in ERDAS Imagine and the clip function in ArcMap. The boundary of the province was extracted from topographic sheets. The final step was selecting the suitable bands in the image set for the subsequent image processing. Four (blue, red, NIR and MIR) out of twelve bands in the MODIS image were stacked together for image classification. The single-band SRTM image was used for topographic analysis. Two (red and NIR) bands in each Landsat (MSS, TM, and ETM+) image were stacked together for NDVI estimation.

\subsection{Image Classification}

Generally, Hail region consists of mountains and valleys, extensive plains and plateaus, sand dunes and cultivated lands. Urban areas usually occur in plain expanses. The DEM image was categorized in ArcMap into 10 elevation classes (between $700-1500 \mathrm{~m}$ ) with $100 \mathrm{~m}$ interval to produce themtic topographic map. The purpose of the MODIS image classification is to prepare a land cover map to the study area. The spectral characteristics of the major land cover units within the study area have been explored before applying the image classification. Classification of the MODIS 2010 image proceeded as follows. A total of 100 clusters were performed using the ISODATA (Iterative Self-Organizing Data Analysis) classification to the $95 \%$ convergence threshold, using the blue, red, NIR and MIR stacked MODIS image. To label the classified clusters, the original MODIS image and the clustered image were displayed side by side on the computer screen and then spatially linked together to facilitate labeling process to four types of clusters: mountains, plains, vegetation and sand dunes. After labeling, pixels pertaining to each class were recoded together. A majority filter window $(3 \times 3)$ was applied to remove odd pixels and the number of pixels belonging to each class was counted and converted to actual surface area.

\subsection{Classification Accuracy}

Accuracy is typically used to express the degree of correctness of thematic maps [16]. Thus it was crucial to

Table 1. The satellite images utilized in the present study. Source: USGS.

\begin{tabular}{ccccc}
\hline Sensor & Date & Spatial Resolution, m & Spectral Resolution & Swath, km \\
\hline MSS & Nov. 1972 & 60 & 4 bands & 185 \\
TM & Sept. 1987 & 30 & 7 bands & 185 \\
SRTM & Feb. 2000 & 1000 & 1 band & Global \\
ETM+ & Aug. 2000 & 30 & 7 bands & 12 bands \\
MODIS_VI & Aug. 2010 & 250 & & 2330 \\
\hline
\end{tabular}


examine the accuracy of the land cover map generated from the unsupervised classification process. We applied a classification accuracy assessment for the 2010 land cover map to determine each class accuracy compared with its real existence as recorded in the original MODIS by choosing stratified random 100 sample points distributed in the original image using the stratified random scheme. The producer and the user accuracies as well as the kappa statistics for each class were calculated.

\subsection{Agricultural Land Change Detection}

The most obvious method of change detection is a comparative analysis of spectral information of two or more images produced independently at different times [15]. Since there is a strong correlation between NDVI and the green vegetation [17], mapping agricultural land in Hail region between 1972 and 2000 was carried out by applying the NDVI to the Landsat MSS, TM, ETM+ images.

After applying the NDVI algorithm, assigning the threshold of green vegetation was carried out carefully to highlight pixels representing cultivated lands at the time of each image acquisition date (1972, 1987 and 2000). Pixels having values equal and greater than the threshold values were clustered together and counted as cultivated lands at each Landsat image.

\section{Results and Discussion}

The arid climate, land cover variations and the clear sky of Hail are the main reasons for a successful remote sen- sing of the region. The digital elevation model of Hail reveals a regional southwest to northeast terrain sloping due to the existence of Hail region upon a structurally north plunging fold known as Hail Arc, which extends to Iraq in the northeast [18]. This arc is a result of folding effect related to the opening of the Red Sea and Gulf of Aden rifts [19]. Maximum elevation in Hail occurs at the extreme southwest corner of the province approaching more than $1900 \mathrm{~m}$ above the mean sea level (asl) at Jabal Al-Eklil $\left(25^{\circ} 55^{\prime} \mathrm{N}\right.$ and $\left.39^{\circ} 58^{\prime} \mathrm{E}\right)$. Other peaks of the province are represented by Aja (1480 $\mathrm{m}$ asl) and Salma mountains (1300 $\mathrm{m}$ asl) at the middle part of the province (Figure 2). Hail City, the capital, occurs at $900-1000 \mathrm{~m}$ asl. The land north of Hail City gradually tilts in a northeast direction. Minimum level of land ranges between 600 and $700 \mathrm{~m}$. The extensive Nafud sand dunes atop a plateau land of 700 to $900 \mathrm{~m}$ asl. Major cultivated lands occur at the east of Hail and extend to Al-Qasim at elevations ranging from 700 to $900 \mathrm{~m}$ asl.

The unsupervised classification of the MODIS 2010 image produced 4 classes: plains, sand dunes, mountains and cultivated lands. The overall accuracy of this land cover map approached $94 \%$ with maximum producer and user accuracies recorded for vegetation (100\%) (Table 2). The minimum producer and user accuracies were recorded for plains $(90 \%$ and $82 \%$, respectively). Kappa statistics were generally high, with maximum for vegetation (1.0) and minimum for mountains (0.75). The land cover map of Hail (Figure 3 and Table 2) reveals that the total area is $115,690 \mathrm{~km}^{2}$.

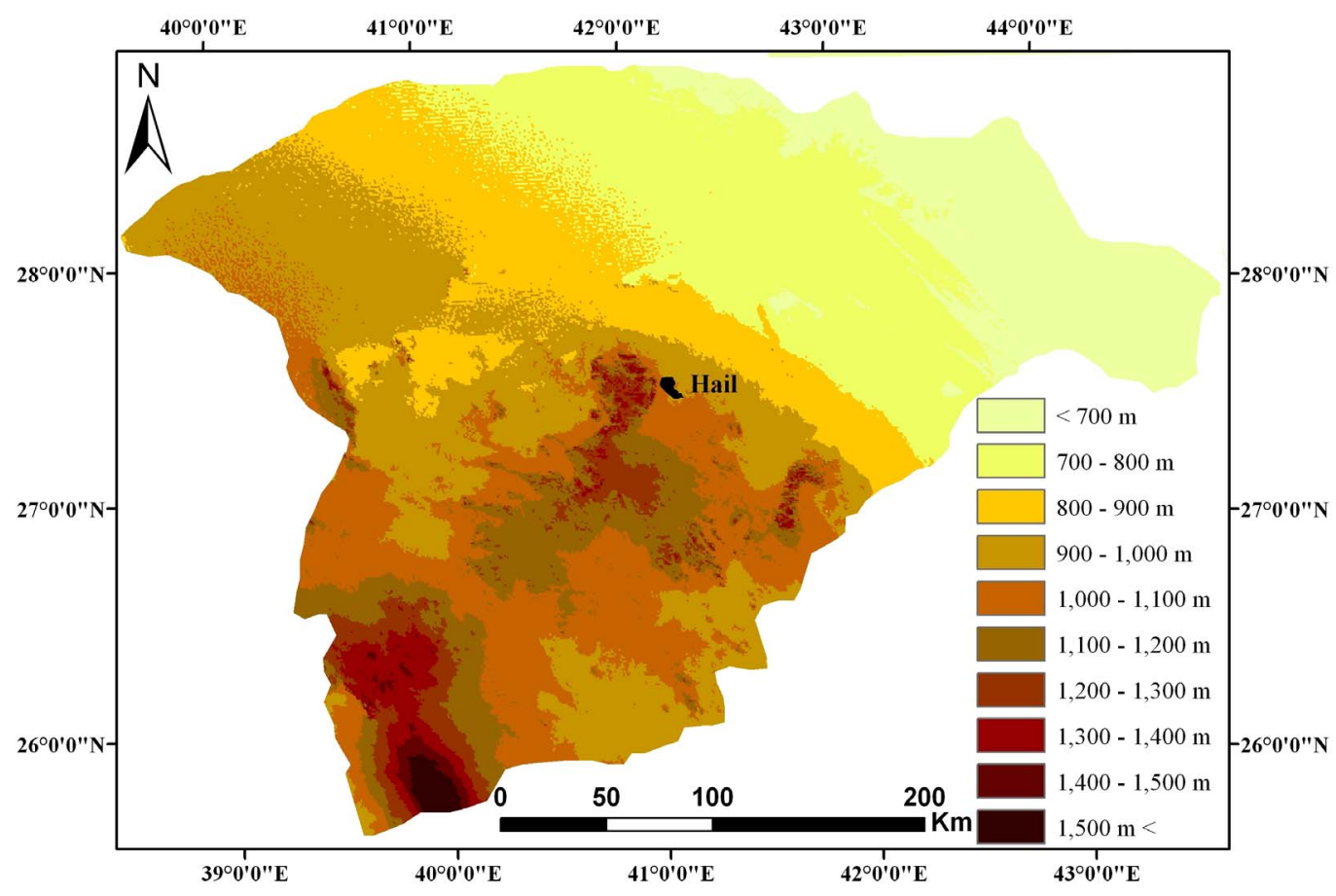

Figure 2. Topographic map of Hail region as obtained from the SRTM DEM. 


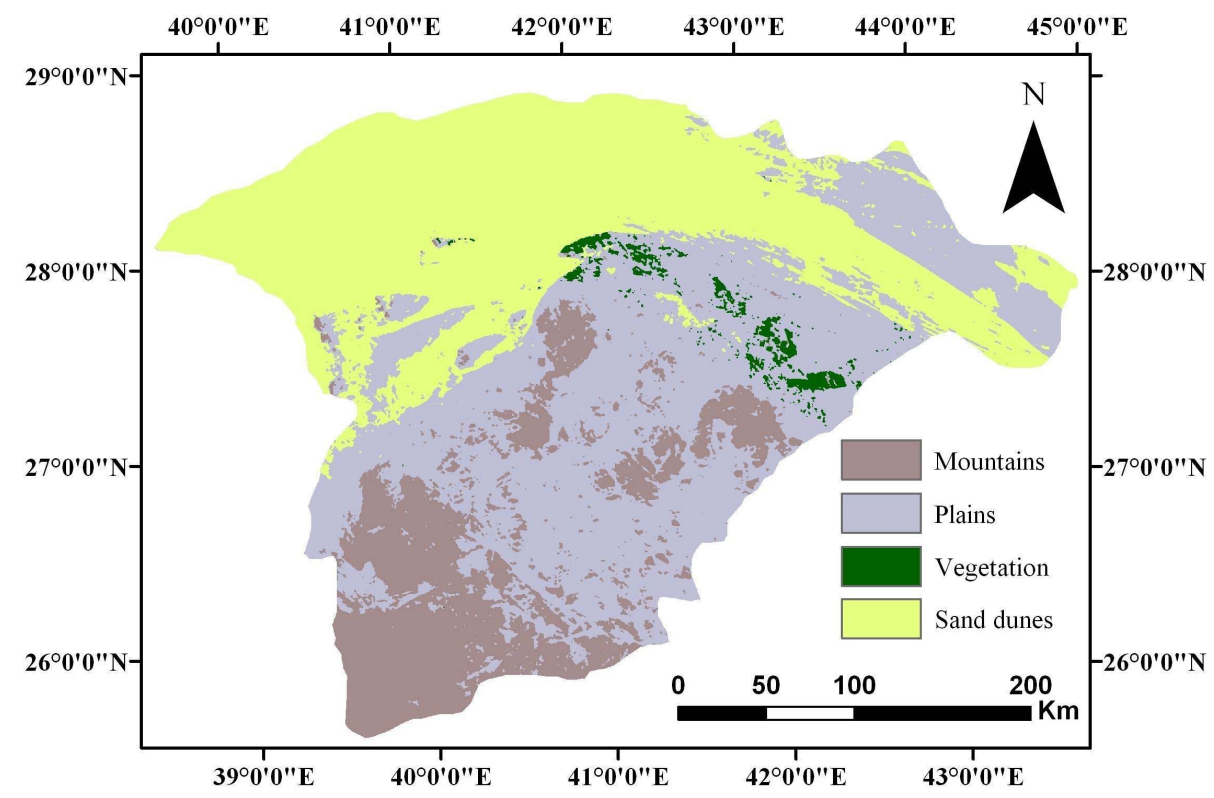

Figure 3. Land cover map of Hail as obtained from MODIS 2010 image.

Table 2. Land cover units of Hail Province and their accuracy estimation.

\begin{tabular}{ccccc}
\hline & Area $\left.\mathbf{( 1 0 0 0} \mathbf{~ k m}^{\mathbf{2}}\right)$ & Producer accuracy & User accuracy & Kappa statistics \\
\hline Plains & 55.27 & 90 & 82 & 0.77 \\
Sand dunes & 40.65 & 91 & 100 & 1 \\
Mountains & 18.38 & 77 & 77 & 0.75 \\
Vegetation & 01.39 & 100 & 100 & 1 \\
Total & $\mathbf{1 1 5 . 6 9}$ & & $\mathbf{9 4}$ & $\mathbf{0 . 9 1}$ \\
\hline
\end{tabular}

Plains, where urban areas and infrastructures are settled, occupy 55,270 $\mathrm{km}^{2}(47.77 \%)$. Most famous urban centers in Hail are: Baqaa; Al-Ghazalah; Al-Shinan; Jubbah; Mowqaq; Faid; Al-Rowdah; Al-Halifah; Al-Hait; Al-Khitta; and Umm Al-Qulban. Generally, there are four main highway routes crossing Hail Province, connecting the major cities and passing the capital city: HailBuraydah; Hail-Tabouk; Hail-Al-Madinah Al-Monawara; and Hail-Baqaa.

There are many dry streams in Hail, which make up a network of dense drainage systems. The main streams in Hail are: Wadi Al-Aderaa, which extends in a southwestnortheast direction for $160 \mathrm{~km}$ and ending at Baqaa; Wadi Al-Ish; Wadi Al-Sheebah; Wadi Al-Remmah; and Wadi Al-Ghar. The government built many dams at the mouths of the main streams to control water flooding after torrential storm; such as Eqda, Al-Wasimy; Neqbeen Dams at the foot of Aja Mountain in the city of Hail. Large areas of Hail are covered by surfacial deposits of the Quaternary age, such as sabkhas, alluvium and lag deposits.

Sand dunes cover $40,650 \mathrm{~km}^{2}(35.13 \%)$. This dune field is a part from the Nafud Sand Sea, which occupies
$75 \times 10^{3} \mathrm{~km}^{3}$ and forms the second sand sea in the Arabian Peninsula [20]. Sands in this dune field are stained by the red color due to the occurrence of iron oxides as they were derived from the extensive outcrops of the Lower Palaeozoic ferruginous sandstones at the northwest and west corners of the sand sea [13]. Major dune forms in this sand sea belong to the longitudinal dunes, which are more or less parallel to the prevailing N-S wind direction. Sand dunes occasionally encroach upon cultivated lands and people settlements, particularly after heavy sand storms, which are most frequent during spring and winter seasons (Figure 4(a)).

Mountains occupy 18,380 $\mathrm{km}^{2}(15.88 \%)$. Mountains of Hail are rugged and mainly composed of Precambrian igneous and metamorphic rocks as well as Phanerozoic sedimentary outcrops (Figure 4(b)). The igneous rocks mainly include granitoid, granodiorite, diorite, gabbro, ultramafic rocks and their equivalent volcanic varieties, such as rhyolite, ignmbrite, andesite, and basalt. Metamorphic rocks comprise gneiss, schist, marble and serpentinite rocks [11]. Clastic sedimentary rocks cover significant area of Hail, particularly at the eastern and northeastern sections. One of the most obvious geologic fea- 
tures in Hail is the presence of Cenozoic (1.8 Ma) volcanic craters or calderas (Harrat in Arabic) displaying several basaltic lava flows, volcanic vents, tuff rings and cinder cones of alkali olivine basaltic composition [21] (Figure 4(c)). These calderas are mainly structurally controlled by tectonic rifting of the Red Sea [22]. Economic mineral deposits in Hail include tin, tungsten, gold-bearing quartz, zinc, niobium, rare-earth minerals, molybdenum, chromium, nickel, magnetite, fluorite, and gemstones associated with the Arabian Shield basement rocks, whereas kaolinite, phosphate, sub-bituminous coal, glass sand and building stones are related to sedimentary suits of the region [11].

Cultivated lands only represent $1390 \mathrm{~km}^{2}$ (139,000 ha) of the province in 2010. Crops are cultivated under controlled center pivot irrigation (Figure 4(d)). Major crops are alfalfa, tomatoes, peaches, apricot, melon, olive, wheat, and orange. Agricultural land change is observed clearly in Landsat images (Figure 5). It is obvious that during the 1970s, there were no cultivated lands in the region, except for natural vegetation and date palm groves. As early as 1980s, agricultural development projects had started and reclamation of new desert land continued until 2010. Areas of cultivated lands as obtained from the NDVI algorithms and MODIS image classification are estimated at $9500 \mathrm{ha} ; 37,700 \mathrm{ha} ; 69,400 \mathrm{ha}$; and 139,300 ha in 1972, 1987, 2000 and 2010, respectively. Due to the arid nature of Hail, groundwater is the primary source
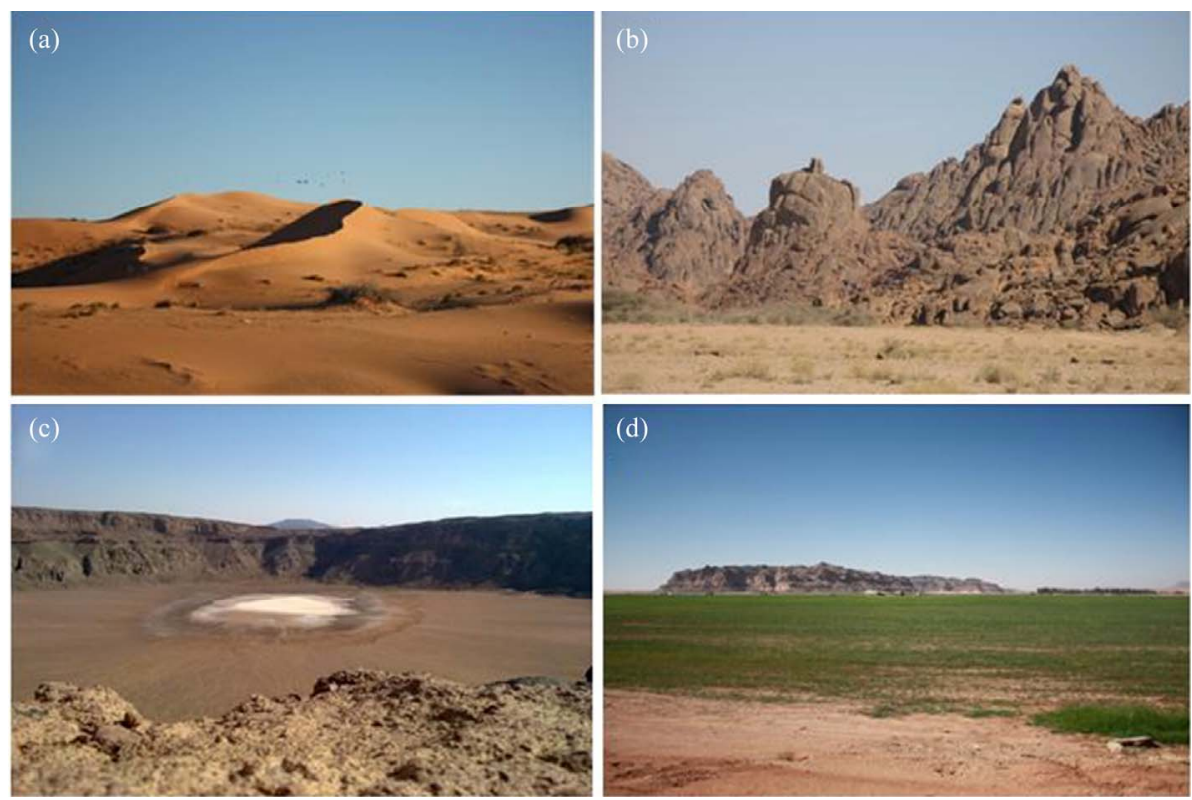

Figure 4. (a) is a part of the Nafud Sand Sea; (b) is Aja Mountain west of Hail City; (c) is a volcanic crater (Harra) south of Hail and (d) is a cultivated field irrigated by center pivot system.
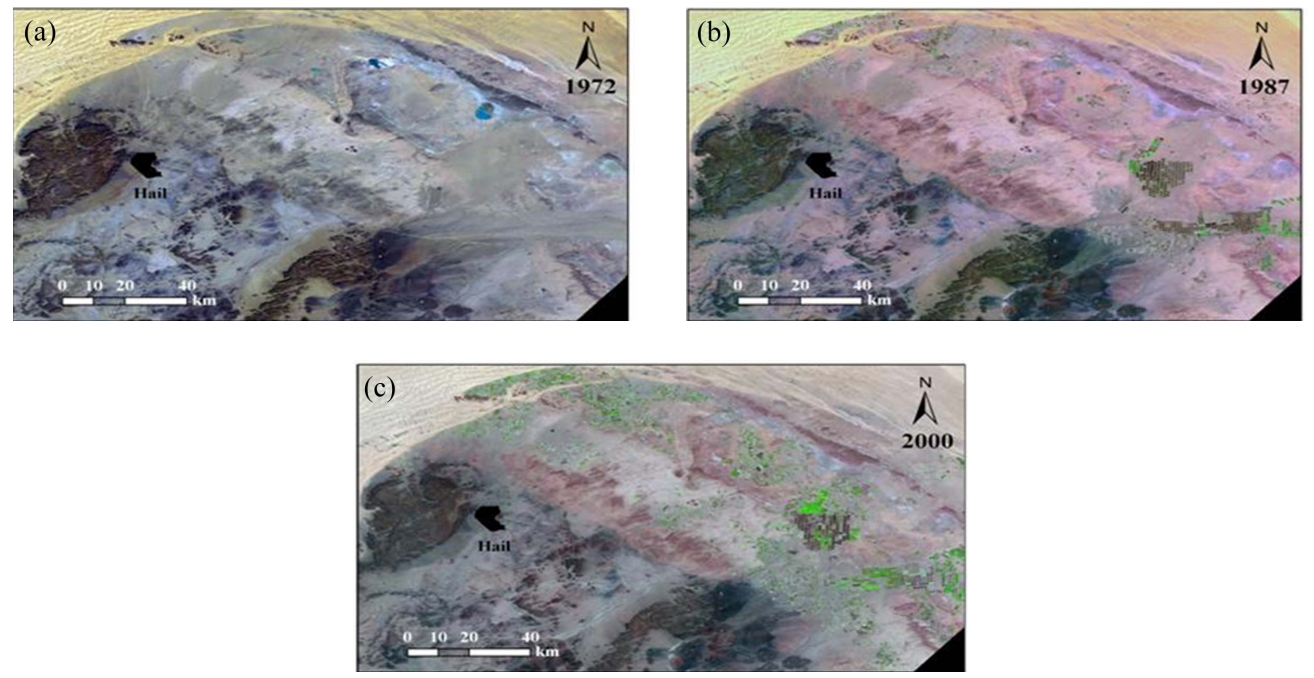

Figure 5. (a), (b) and (c) show the change of Hail cultivated lands in 1972, 1987 and 2000, respectively. 
for irrigation. Previous studies [23] reported that the Saq aquifer stores as much as 280,000 million cubic meters of water reserves with water salinity ranges between 300 1000 ppm [24].

\section{Conclusion}

Hail region has been surveyed from space using different generations of satellite data. The primary conclusion of the present study ascertains the importance of using remote sensing for mapping desert geomorphology at a regional scale. Hail has a promising development future. The region is rich in economic mineral deposits and has a significant potentiality for national tourism. As agriculture is significantly growing in this arid region, detailed hydrogeological studies are needed in terms of its quantity and quality for irrigation. Moreover, the drifting sand from the northern Nafud Sand Sea entails detailed studies to recognize their patterns and magnitude of encroachment because they cause series problems to settlements and infrastructures.

\section{REFERENCES}

[1] F. Yuan, K. Sawaya, B. Loeffelholz and M. Bauer, "Land Cover Classification and Change Analysis of the Twin Cities (Minnesota) Metropolitan Area by Multitemporal Landsat Remote Sensing," Remote Sensing of Environment, Vol. 98, 2005, pp. 317-328.

doi:10.1016/j.rse.2005.08.006

[2] A. Collado, E. Chuvieco and A. Camarasa, "Satellite Remote Sensing Analysis to Monitor Desertification Processes in the Crop-Rangeland Boundary of Argentina," Journal of Arid Environments, Vol. 52, No. 1, 2002, pp. 121-133.

[3] A. Prakash, and R. Gupta, "Land-Use Mapping and Change Detection in a Coal Mining Area-A Case Study in the Jharia Coalfield, India," International Journal of Remote Sensing, Vol. 19, No. 3, 1998, pp. 391-410. doi:10.1080/014311698216053

[4] Q. Cheng, "Multisensor Comparisons for Validation of MODIS Vegetation Indices," Pedosphere, Vol. 16, No. 3, 2006, pp. 362-370. doi:10.1016/S1002-0160(06)60064-7

[5] M. Hereher, "Vulnerability of the Nile Delta to Sea Level Rise: An Assessment Using Remote Sensing," Geomatics, Natural Hazards and Risk, Vol. 1, No. 4, 2010, pp. 315321. doi:10.1080/19475705.2010.516912

[6] A. Masoud and K. Koiki, “Arid Land Salinization Detected by Remotely-Sensed Landcover Changes: A Case Study in the Siwa Region, NW Egypt," Journal of Arid Environments, Vol. 66, No. 1, 2006, pp. 151-167. doi:10.1016/j.jaridenv.2005.10.011

[7] D. Fuller, "Trends in NDVI Time Series and Their Relation to Rangeland and Crop Production in Senegal, 19871993," International Journal of Remote Sensing, Vol. 19, No. 10,1998 , pp. 2013-2018. doi:10.1080/014311698215135
[8] J. Rouse, R. Has, J. Schell and D. Deering, "Monitoring Vegetation Systems in the Great Plains with ERTS," Proceedings 3rd Earth Resources Technology Satellite-1 Symposium, Greenbelt, NASA SP-351, 1974, pp. 30103017.

[9] E. Weiss, S. E. Marsh and E. S. Pfirman, "Application of NOAA-AVHRR NDVI Time-Series Data to Assess Changes in Saudi Arabia's Rangelands," International Journal of Remote Sensing, Vol. 22, No. 6, 2001, pp. 1005-1027. doi:10.1080/014311601300074540

[10] E. Symeonakis and N. Drake, "Monitoring Desertification and Land Degradation over Sub-Saharan Africa," International Journal of Remote Sensing, Vol. 25, No. 3, 2004, 573-592. doi:10.1080/0143116031000095998

[11] B. Ekren, D. Vaslet, A. Berthiaux, P. Strat and J. Fourniguet, "Explanatory Notes to the Geologic Map of the Hail Quadrangle, Sheet 27E, Kingdom of Saudi Arabia," Deputy Ministry for Mineral Resources, Ministry of Petroleum and Mineral Resources, Jeddah, 1986, p. 46.

[12] M. Hussein, A. Bazuhair and A. Ageeb, "Hydrogeology of the Saq Formation East of Hail, Northern Saudi Arabia," Quaternary Journal of Engineering Geology, Vol. 25, 1992, pp. 57-64. doi:10.1144/GSL.QJEG.1992.025.01.05

[13] H. Edgell, “Arabian Deserts: Nature, Origin, and Evolution," Springer, Dordrecht, 2006. doi:10.1007/1-4020-3970-0

[14] P. Chavez, "Image-Based Atmospheric Correction-Revised and Improved," Photogrammetric Engineering and Remote Sensing, Vol. 62, No. 9, 1996, pp. 1025-1036.

[15] A. Singh, "Digital Change Detection Techniques Using Remotely-Sensed Data," International Journal of Remote Sensing, Vol. 10, No. 6, 1989, pp. 989-1003. doi:10.1080/01431168908903939

[16] G. Foody, "Status of Land Cover Classification of Accuracy Assessment," Remote Sensing of Environment, Vol. 80,2002 , pp. $185-201$. doi:10.1016/S0034-4257(01)00295-4

[17] C. Tucker, "Red and Photographic Infrared Linear Combination for Monitoring Green Vegetation," Remote Sensing of Environment, Vol. 8, 1979, pp. 127-150. doi:10.1016/0034-4257(79)90013-0

[18] A. Al-Laboun, "The Subsurface Stratigraphy of Pre-Khuff Formations in Central and Northwestern Arabia," Ph.D. Thesis, Faculty of Earth Sciences, King Abdulaziz University, Jeddah, 1982.

[19] P. Burek, "Structural Effects of Sea-Floor Spreading in the Gulf of Aden and the Red Sea on the Arabian Shield," In: E. Degens and D. Ross, Eds., Hot Brines and Recent Heavy Metal Deposits in the Red Sea, Springer-Verlag, Berlin, 1969, pp. 59-70.

[20] A. Dabbagh, K. Al-Hinai and M. Khan, "Detection of Sand-Covered Geologic Features in the Arabian Peninsula Using SIR-C/X-SAR Data," Remote Sensing of Environment, Vol. 59, No. 2, 1997, pp. 375-382. doi:10.1016/S0034-4257(96)00160-5

[21] J. Pallister, "Reconnassance Geology of the Harrat Al Hutaymah Quadrangle, Sheet 26/42 A, Kingdom of Saudi 
Arabia," Saudi Arabian Deputy Ministry for Mineral Resources, Jeddah, 1986, p. 77.

[22] R. Coleman, R. Gregory and G. Brown, "Cenozoic Volcanic Rocks of Saudi Arabia," Saudi Arabian Deputy Ministry for Mineral Resources, Jeddah, 1983, p. 82.

[23] J. Lloyd and R. Pirn, "The Hydrogeology and Groundwater Resources Development of the Cambro-Ordovician
Sandstone Aquifer in Saudi Arabia and Jordan," Journal of Hydrology, Vol. 121, 1990, pp. 1-20. doi:10.1016/0022-1694(90)90221-I

[24] M. Sharaf and M. Hussein, "Groundwater Quality in the Saq Aquifer, Saudi Arabia," Hydrology Sciences Journal, Vol. 41, No. 5, 1996, pp. 683-696. doi: $10.1080 / 02626669609491539$ 